\title{
Differences in conductive foot cooling: a comparison between males and females
}

Heather Lunt and Michael Tipton

Extreme Environments Laboratory, Department of Sport and Exercise Science, University of Portsmouth, UK.

Running Header: Conductive foot cooling

Corresponding author:

Heather Lunt

Extreme Environments Laboratory

Department of Sport and Exercise Science

University of Portsmouth

Spinnaker Building

Cambridge Road

PORTSMOUTH

PO1 2ER

UK

heather.lunt@port.ac.uk

telephone +442392843545

fax +442392843620 


\section{Abstract}

Purpose: This study investigated possible sex-related and intra-menstrual differences in local vascular and skin temperature responses when conductive cooling was applied to the soles of the feet.

Method: Twelve females and twelve males exposed the soles of their feet to a cooling plate (which cooled from $35^{\circ} \mathrm{C}$ to $15^{\circ} \mathrm{C}$ ) on two occasions $12-15$ days apart. For females, sessions took place during their inactive and active contraceptive pill phases. Tip of Great toe temperature and Great toe skin blood flow were recorded throughout.

Results: Females' feet cooled to a greater extent than males' $(P=0.001)$. Sensitivity of toe skin blood flow to changes in skin temperature $\left(1^{\circ} \mathrm{C}\right.$ or $\left.2^{\circ} \mathrm{C}\right)$ was not different between males and females. Dimensions of males' feet were larger than females' $(P<0.05)$ and correlations between foot dimensions and toe skin cooling were found $(r=0.728, P<0.001)$. Analysis of the residual variance showed that foot volume, contact area and skin blood flow correlated with the rate of toe skin cooling $\left(r=0.812, r^{2}=0.659, P<0.001\right)$. No intra-menstrual differences were found.

Conclusion: The feet of females cooled at a faster rate than those of males in response to the same conductive cooling stimulus to the soles of the feet. However, similar reductions in skin blood flow were found for the same change in toe skin temperature. Therefore, sex related differences may be due to the differing dimensions of the feet, but further research including males and females matched for foot dimensions are required to confirm this mechanism.

Keywords: Skin blood flow, Skin temperature, Sex-related differences, Intra-menstrual differences

Abbreviations:

$\mathrm{NFCl}$ : Non freezing cold injury

TS: Temperature sensation

TC: Thermal comfort

ANOVA: Analysis of variance

\section{Introduction}

The local vascular response to cooling is vasoconstriction, which can occur in response to cold stimulation and thus cools the limb but reduces further heat loss. This cutaneous vascular response to local hand and forearm cooling is greater in females than males (Bartelink, de Wit, Wollersheim, Theeuwes, \& Thien, 1993; Cooke, Creager, Osmundson, \& Shepherd, 1990). The mechanisms of this response have been linked to hormonal status (Bartelink et al., 1993), 
local vascular mechanisms involving $\alpha_{2}$ adrenoreceptors (Canker \& Finderle, 2003) or the effect that hormonal status has on the sympathetic nervous system (Colucci, Gimbrone, McLaughlin, Halpern, \& Alexander, 1982; Mercuro et al., 1999). In addition, these studies have also shown greater vasoconstrictor responses in the hands and forearms of females during the luteal menstrual phase compared to the follicular menstrual phase. Further gender differences include blood flow, Cooke et al. (1990) found skin blood flow to be three times greater in males than females. Consequently, as blood perfusion of the periphery maintains skin temperature, the more pronounced cutaneous vasoconstrictor response observed in the hands and forearms results in lower skin temperatures of females compared to males (Reading, Roberts, \& Prusaczk, 1997). Equally, skin blood flow responses influence skin temperature before contact with a cold object, yet the response to cooling by contact with a cool or cooling object may not be affected by skin blood flow (Jay \& Havenith, 2004c).

Slow cooling of the whole hand was found to be correlated with the size of the palm and hand volume (Rissanen, Rintamaki, \& Group, 2000). More recently differences in finger skin cooling of males and females under 'slow cooling' conditions were investigated (Jay \& Havenith, 2004a, 2004b). They established that there were differences in finger cooling between males and females, with the fingers of females cooling more quickly than males. Rather than any difference in physiological responses, they found that the slower finger cooling observed by males was primarily a function of larger finger and hand size, as a larger hand provides greater heat content and consequently slower skin cooling.

The research conducted in the area thus far has focused on skin temperature and local cooling of the hand and forearm. It is not known if the same mechanisms are responsible for foot cooling. As non-freezing cold injuries (NFCl) most commonly occur in the lower limbs (Imray, Grieve, Dhillon, \& The Caudwell Xtreme Everest Research Group, 2009), if the feet of a group of people cool more than others, this information would indicate a greater susceptibility to $\mathrm{NFCl}$, especially if no action is taken to prevent further heat loss or promote foot 
rewarming. The susceptibility to $\mathrm{NFCl}$ is particularly important to military personnel and those undertaking winter sports who may be exposed to the cold, or when inappropriate footwear for the conditions are worn that allow the feet to become, and remain cold and possibly wet.

The perception of cold stimuli has been investigated in both the hands and feet of adult males and females. The studies established that females were more sensitive to the detection of warmth and coolth on the arm than males (Golja, Tipton, \& Mekjavic, 2003; Harju, 2002), but less perceptive than males when the same stimuli were presented on the soles of the feet (Harju, 2002). This study did not account for differences in menstrual cycle, but more recently site-specific intra-menstrual cycle differences in thermal perceptions were found (Soderberg, Sundstrom Poromaa, Nyberg, Backstrom, \& Nordh, 2006). Cold perception on the breast was more sensitive (cool stimuli detected at warmer skin temperatures) in the late follicular and mid-luteal phases, compared with the early follicular phase. In contrast, no differences related to phase of the menstrual cycle in cold perception or cold pain were found at other sites tested (face and forearm). There are no published data on cold perception during foot cooling of females during different phases of the menstrual cycle. If males and females have different perceptions of cooling of the feet, it may mean that one group takes earlier actions to prevent the feet cooling to the point where cold injuries may occur. Hence it is relevant to establish if males and females have a similar subjective assessment of foot cooling.

The primary aim of the present study was to determine if there are differences in the rate at which the feet of men and women cool when conductive cooling is applied to the soles of the feet, and to establish if these responses can be interpreted as sex-related differences. A secondary aim was to investigate the influence of the menstrual cycle on the rate of foot cooling and thermal perception. Therefore, it was hypothesised that the rate of foot cooling of females would be greater than that of males. Secondly the rate of cooling the feet of females would alter dependent up on menstrual phase, with a greater 
rate of foot cooling during the luteal phase than the follicular phase. Thirdly, females will be less sensitive to the perception of cooling and thermal comfort on their feet than males and finally, there will be no difference in perception of cooling or thermal comfort during different menstrual phases.

\section{Methods}

\section{Subjects}

Twelve males and twelve females aged between 18 and 43 years of age gave their written informed consent to participate in the study that was approved by the University of Portsmouth Bioscience Research Ethics Committee. Their personal characteristics are shown in Table 1. All were healthy and had no history of cold exposure or cold injuries. The females regularly took the combined pill and had regular menstrual cycles (between 28 to 30 days in length). Menstrual cycle phase was calculated from the onset of menses, with testing taking place in the mid-follicular phase (seven days after the onset of menses, inactive pill phase) and mid-luteal phase (21 days after the onset of menses, active pill phase).

\section{Study Design and Procedures}

The volunteers performed the experiment on two separate occasions, males completed the tests 12-15 days apart, and females undertook the experiment during the inactive and active pill phases. On both occasions, participants wore light clothing suitable for moderate cycling exercise (100 W) in a temperature and humidity controlled chamber. The ambient conditions in the chamber were maintained at a mean \pm standard deviation (SD) of $25.0(0.6){ }^{\circ} \mathrm{C}$ dry bulb temperature and 39.2 (7.0) \% relative humidity.

Participants cycled for 12 minutes to ensure they were fully vasodilated prior to the cooling profile, they then sat next to a temperature controlled water perfused footplate warmed to $35^{\circ} \mathrm{C}$. The water temperature perfusing the plate was controlled using a water bath (Grants Instruments [Cambridge] Ltd, UK) and 
chilling units (Grants Instruments [Cambridge] Ltd, UK). The volunteers took off their shoes and socks and rested their feet on the footplate, the surface layer was an Aluminum alloy (6082, T651, thermal conductivity $\left.=180 \mathrm{~W} \cdot \mathrm{m}^{-1} \cdot \mathrm{K}^{-1}\right)$. The Great toe of each foot was then instrumented with a laser Doppler probe (MooreLab, Moore Instruments, UK) on the tip of the toes, and a skin thermistor (Grants instruments [Cambridge] Ltd, UK) on the toe pads. When toe skin blood flow and foot temperatures were stable and warm (recorded for 10 minutes to establish stable readings) footplate cooling was started. Footplate cooling was performed by cooling the water perfusing the footplate from $35^{\circ} \mathrm{C}$ to $15^{\circ} \mathrm{C}$ at an average (SD) rate of $-1.7(0.2)^{\circ} \mathrm{C} \cdot \mathrm{min}^{-1}$. The lower temperature limit of $15^{\circ} \mathrm{C}$ was based on the physiological criteria for pain (Geng et al., 2006). Participants gave their perceptual votes for thermal comfort and temperature sensation at the start and end of exercise, immediately prior to cooling and again after every $5^{\circ} \mathrm{C}$ of plate cooling. If at any point participants' feet became too uncomfortable they removed them from the plate and the test was ended. The change in toe skin temperature was converted into a cooling rate $\left({ }^{\circ} \mathrm{C} \cdot \mathrm{hr}{ }^{-1}\right)$.

\section{Measured and Calculated variables}

\section{Foot measurements}

The surface area of the foot in contact with the plate was calculated by placing volunteers feet on a sensor pad, adopting the same seated posture they had during the data collections, the contact area was calculated using Mat Scan Research Software (version 6.51). The volume of each foot was calculated by displacement, when the foot was immersed to the most prominent part of the external malleolus. Contact area:volume ratio was also calculated. The foot length was measured from the heel to the end of the longest toe, Great toe length was measured from the distal phalangeal joint to the end of the toe and Great toe circumference was measured around the mid-point of the proximal phalanx, all lengths and girths were measured using a metal anthropometry tape (Rosscraft, Canada). 
Ambient temperature was calculated from a dry bulb thermometer (Grant Instruments [Cambridge] Ltd, UK). Ambient relative humidity was calculated from the difference between wet and dry bulb temperatures (Grant Instruments [Cambridge] Ltd, UK) using Antoine's method. Wet and dry bulb temperatures were recorded at minute intervals. Skin temperatures were recorded at $10 \mathrm{~s}$ intervals on the tip and pad of the toe. Skin thickness was not assessed to establish if there were any sex-related differences, however care was taken to avoid placing the thermistors or probes on hard or callused skin.

\section{Skin blood flow}

Laser Doppler probes (Moor Instruments Ltd, UK) were calibrated before each testing session using a microsphere solution provided by the manufacturer. The probes were attached to the tip of the Great toes using tape (Transpore, 3M Healthcare, Germany). If the sites were heavily callused an alternative site as close to the end of the toes was used. The laser Doppler was connected to a data acquisition system (SP 16, AD Instruments, Australia), sampling at 400 samples per second. The data were averaged as minute means. Participants were asked to adopt a comfortable position at the start of each data collection to minimise body movement, especially movement of the toes.

\section{Perceptual variables}

Temperature Sensation (TS): was assessed for the whole body and feet using a 20 $\mathrm{cm}$ visual analogue scale ranging from "Very Hot" $(0 \mathrm{~cm})$; "Hot"; "Warm"; "Slightly Warm"; "Neutral"; "Slightly Cool"; "Cold"; to "Very Cold" (20 cm). N.B: on both thermal perceptual scales the worded descriptions adjacent to the scales will be used as a guide only (Zhang \& Zhao, 2008).

Perception of Thermal Comfort (TC): was assessed for the whole body and feet using a $20 \mathrm{~cm}$ visual analogue scale with the following words used to guide comfort voting: very comfortable $(20 \mathrm{~cm})$, comfortable $(16 \mathrm{~cm})$, just comfortable 

uncomfortable $(0 \mathrm{~cm})$.

In addition, to the regular reports of thermal comfort and temperature sensation, volunteers were asked to indicate when they no longer felt thermally comfortable and the footplate and toe temperatures at this point were recorded.

\section{Data analyses}

Laser Doppler data were normalised with $100 \%$ being the resting component following cycling. The rate of cooling $\left({ }^{\circ} \mathrm{C} \cdot \mathrm{hr}^{-1}\right)$ was also calculated from the change in skin temperature over the duration of the study. All data were calculated as means and standard deviations (SD) at minute intervals during the study and at intervals of $5^{\circ} \mathrm{C}$ of footplate cooling to coincide with the timing of subjective votes.

\section{Statistical analyses}

Statistical analysis was performed using IBM SPSS Statistics Version 20. The data were assessed for normality of distribution. Comparisons between males first and second visits and between the females visits during inactive and active pill phases were made separately for toe skin temperature, skin blood flow and the perceptual votes using repeated measures ANOVAs (visit [2] $x$ variable at a given footplate temperature [6]) that were corrected for multiple comparisons (Bonferroni adjustment), analysis was performed at the start of the test and for every $5^{\circ} \mathrm{C}$ of foot plate cooling (from $35^{\circ} \mathrm{C}$ to $15^{\circ} \mathrm{C}$ ), $n=12$ males and females except when the foot plate was at $15^{\circ} \mathrm{C}$ where $n=12$ males and 10 females, two females withdrew from the experiment at footplate temperatures of $17.6^{\circ}$ and $19^{\circ} \mathrm{C}$. Their discomfort was temporary and all participants left the laboratory having regained comfort and sensation within their feet.

A mixed model ANOVA (sex [2] $x$ footplate temperature [5]) with post-hoc independent samples t-tests (repeated factor of footplate temperature, non repeated factor of sex, corrected for multiple comparisons [Bonferroni 
adjustment]) was used to identify the separate main effects of sex at different footplate temperatures. This analysis was performed at the start of the test and for every $5^{\circ} \mathrm{C}$ of footplate cooling. Mixed model ANOVAs (sex [2] $x$ toe skin temperature [6]) with post-hoc independent samples t-tests (repeated factor of toe skin temperature, non repeated factor of sex, corrected for multiple comparisons [Bonferroni adjustment]) were used to identify the separate main effects or interaction effects of sex and toe skin temperature on skin blood flow and perceptual votes. This analysis was performed at the at toe skin temperatures between $32.5^{\circ} \mathrm{C}$ and $30.0^{\circ} \mathrm{C}$ and for every $0.5^{\circ} \mathrm{C}$ decrement between these temperatures. A further mixed model ANOVA was used to identify any main or interaction effects of the sensitivity of the skin blood flow response to changes in skin temperature (sex [2] $x$ change in skin blood flow at $1^{\circ} \mathrm{C}$ and $2^{\circ} \mathrm{C}$ change in skin temperature [2]) with post-hoc independent samples t-tests (repeated factor of toe skin temperature, non repeated factor of sex, corrected for multiple comparisons [Bonferroni adjustment]).

Mann Whitney $U$ tests were performed to establish if there were differences in the dimensions of the feet of males and females. In addition, the toe skin temperature at which male and female volunteers lost thermal comfort was compared using an independent t-test.

Spearman's correlation coefficients were used to correlate cooling rates with foot dimensions. A forward stepwise linear regression model was used to investigate the relationship between the rate of toe skin cooling, skin blood flow, menstrual cycle phase, foot dimensions including contact area:volume ratio. The model incorporated rate of toe skin cooling and analysis of the residual variance for the effects of foot dimensions (using the measurements recorded in table 1), change in toe skin blood flow, thermal comfort, temperature sensation and sex (males given the category code 1 and females code as 2). A further stepwise regression model investigated temperature sensation and thermal comfort and the variance explained by the variables detailed above. Statistically significant differences were accepted at an $\alpha \leq 0.05$. 


\section{Results}

\section{Repeated testing and Intra-menstrual differences}

There were no differences in toe skin temperature, skin blood flow or perceptual votes between the males first and second visits and between their right and left feet $(P>0.05)$. The same was also true for female participants, as there were no differences between the visits during the inactive and active pill phases and between their right and left feet $(P>0.05)$. As there were no differences between visit number or left and right feet of volunteers, the data presented from this point on will be an average of both feet during the first and second visits.

\section{Differences in foot cooling: the effect of sex}

Overall, there was no main effect of sex on toe skin temperature; on the other hand there was a sex $x$ footplate temperature interaction effect $(P<0.001)$. At a footplate temperature of $35^{\circ} \mathrm{C}$ there was no effect of sex on toe skin temperature. Whereas, cooling the sole of the foot resulted in a greater reduction in toe skin temperature of females compared to males (Figure 1). The greater reduction in toe skin temperatures of females compared to males began when the water perfusing the plate was at $30^{\circ} \mathrm{C}(P=0.008)$ and continued for the remainder of the test (through to a foot plate temperature of $15^{\circ} \mathrm{C}, P=0.001$ ).

There was no main effect of sex on toe skin blood flow, however there was a sex $x$ footplate temperature interaction $(P<0.001)$. At the start of the test (foot plate temperature $35^{\circ} \mathrm{C}$ ) there was no effect of sex on toe skin blood flow, whereas, at footplate temperatures of $20^{\circ} \mathrm{C}$ and $15^{\circ} \mathrm{C}$, the toe skin blood flow of females was significantly lower than that of the feet of males $\left(20^{\circ} \mathrm{C}, P=0.002\right.$ and $15^{\circ} \mathrm{C}$, $P=0.001$, respectively). In addition a significant sex $x$ toe skin temperature interaction was found, the toe skin blood flow response of females was reduced to a greater extent than that of males, being significantly lower than males after the tip of toe skin temperature had cooled by $31.5^{\circ} \mathrm{C}(P=0.004$, Figure 2$)$. The change in skin blood flow was also correlated with changes in great toe skin temperature (for males $r=0.343, P=0.138$ and for females $r=0.112, P=0.365$ and 
combined $r=0.566, P=0.002)$. In fact, when assessing the change in skin blood flow response to reductions in toe skin temperature of $1^{\circ} \mathrm{C}$ and $2^{\circ} \mathrm{C}$, there were no differences between males and females (for a $1^{\circ} \mathrm{C}$ fall in skin temperature, the reduction in skin blood flow of males great toes was $31.3 \%$ [18.3\%] and for females $37.3 \%$ [13.4\%], a $2{ }^{\circ} \mathrm{C}$ fall in skin temperature resulted in a $42.9 \%$ [26.5\%] reduction in skin blood flow of males ands $45.7 \%$ [23.2\%] reduction in females, Figure 3).

\section{Differences in foot cooling: the effect of foot dimension}

The volunteers participating in this study were representative of the general population in relation to their foot dimensions when compared to a recent anthropometry database (People Size, 2008 anthropometry software, available from http://www.openerg.com/). Consequently, there are differences between males and females foot dimensions, with females in this study having significantly smaller foot and great toe dimensions than the males (Table 1). Therefore, the greater cooling rates of females compared to males maybe due to females smaller foot dimensions. For instance, correlations (Table 2) were found between the rate of toe cooling and foot volume $(r=0.728, P<0.001$, Figure 4$)$, foot length $(r=0.635, P<0.001)$, great toe length $(r=0.590, P=0.001)$ and great toe circumference $(r=0.650, P<0.001)$. Similarly, correlations between skin blood flow and foot dimensions using both males and females together suggest skin blood flow responses were related to the foot dimension rather than the sex of the individual per se (Table 2). Moreover, male and female volunteers with similar foot dimensions also had similar rates of toe skin cooling and similar reductions in skin blood flow when great toe skin temperature had fallen by $1^{\circ} \mathrm{C}$ and $2^{\circ} \mathrm{C}$ (Table 3).

Whilst a number of foot measurements were found to correlate with the rate of toe skin cooling, these measurements were highly correlated as they are measured from the same foot. Further analysis showed that sex (Males coded 1 and females coded 2) was strongly correlated with foot volume ( $r=-0.867$, $P<0.001)$, foot length $(r=-0.862, P<0.001)$, great toe length $(r=-0.849, P<0.001)$, 
great toe circumference $(r=-0.832, P<0.001)$ and moderately correlated with contact area $(r=0.710, P<0.001)$. Consequently, dimensions of the foot were included in the regression model above sex (sex was a strong co-variate and explained less of the variance than foot dimensions). Foot volume, contact area and skin blood flow at the end of the cooling period were returned by the regression model as explaining the most variance on toe skin cooling $(r=0.812$, $\left.r^{2}=0.659, P<0.001\right)$, with foot volume showing the stronger impact.

\section{Subjective responses to cooling}

Between male and female volunteers, there was no difference in toe skin temperature at which thermal comfort was lost $(P>0.05$, Figure 5). Moreover, when toe temperatures of males and females were similar, thermal comfort votes did not differ. In addition, there was no correlation between sex and thermal comfort votes $(r=-0.271, P=0.100)$, and sex and temperature sensation $(r=-0.238, \mathrm{P}=0.120)$, whereas foot volume and great toe circumference were correlated with temperature sensation (Table 2). Regression analysis investigating thermal comfort returned the Great toe circumference as the model explaining the most variance $\left(r=0.618, r^{2}=0.382, P=0.002\right)$.

There were no relationships between the rate of toe skin cooling and thermal comfort when analysed in single sex groups or as a combined group (males $r=-$ 0.238, $P=0.228$; females $r=0.014, P=0.438$; all $r=0.008, P=0.485)$. Similarly there were no correlations between the rate of toe skin cooling and temperature sensation when analysed as single sex groups (males $r=0.091, P=0.389$; females $r=0.235, P=0.231)$. Whereas, there was a weak, but significant correlation between the rate of toe skin cooling and temperature sensation when the male and female groups were combined $(r=0.476, P=0.035)$, indicating that there is a weak relationship between rates of cooling and perceptual votes, for instance a slower rate of toe skin cooling is related to warmer perceptual votes, and a faster rate of toe skin cooling to colder perceptual votes.

\section{Discussion}


Initially, the data from the present study appears to indicate that the feet of females cool at a faster rate than those of males in response to standardized conductive cooling of the soles of the feet. The feet of females in the study did cool to lower temperatures and skin blood flow was reduced to a greater extent by the end of the data collection. Whilst, this study cannot rule out sex as the primary influence on the rate of skin cooling, there is evidence to suggest that sex per se, is not the main influence. When fully vasodilated, females had cooler toe skin temperatures than males, as vasoconstriction occurs in response to a stimulus rather than an absolute skin temperature (Nilsson, Tenland, \& Oberg, 1980), the sensitivity of skin blood flow for a $1^{\circ} \mathrm{C}$ and $2^{\circ} \mathrm{C}$ change in toe skin temperature showed similar reductions in toe skin blood flow of males and females (Figure 3). Moreover, regression analysis and correlations indicate that the relationship between foot cooling and sex is likely to be mediated by the dimensions of the feet and the area in contact with the cooling surface. However, the volunteers participating in this study were representative of the average male and female in terms of their foot dimensions that were compared with an anthropometry database (People Size, 2008). The foot measurements recorded showed that males had significantly larger foot dimensions than females. The laws of physics would suggest that larger feet have a greater heat content than smaller feet. Consequently, larger feet (of males or females) may take longer to cool than smaller feet. Yet, without comparisons between males and females with similar foot dimensions, the first hypothesis cannot be answered fully.

The initial findings of the present study suggest there was a greater and earlier reduction in the skin blood flow of the Great toes of females compared to males in response to the same cooling stimulus (foot plate temperature, Figure 2), this agrees with the work of Bartelink et al., (1993). In the present study, males and females were representative of their populations, males having larger feet than females. However, in this study several male and female participants had similar foot volumes (Table 3), and the rate at which the skin of their toes cooled and skin blood flow sensitivity to $1^{\circ} \mathrm{C}$ and $2^{\circ} \mathrm{C}$ reductions in toe skin temperature 
were similar, this later finding disagrees with the work of Bartelink et al., (1993). Considering the whole sample, it may be that the greater reduction in toe skin blood flow of the feet of females was due to the greater cooling stimulus (greater reductions in toe skin temperature) they experienced, compared to the males. Consequently, the present study agrees with the findings of Rissenan (2000) and Jay \& Havenith (2004a, 2004b) who showed differences in hand and finger cooling were related to the dimensions of the hand and finger. The present study extends their work to foot cooling. However, research matching males and females for foot dimensions is required to confirm this hypothesis.

Individuals with smaller feet may experience mild or moderate foot cooling and vasoconstriction more regularly as their feet may cool more quickly when exposed to cold stimuli. Repeated exposure of feet to cold stimuli may sensitize the feet, resulting in a greater reduction in skin blood flow, and the feet cooling more quickly. A moderate correlation found in the present study between the rate of toe skin temperature cooling and toe skin blood flow may be indicative of the sensitivity of the vasoconstrictor response to cooling. Such cold sensitization is a common symptom of $\mathrm{NFCl}$ and a pre-cursor to more significant problems (Davey, Eglin, House, \& Tipton, 2013). Alternatively, regular exposure of the extremities to cold can produce an "insulative" acclimatisation in which blood flow is reduced to the extremities to help preserve deep body temperature (Brown, Hatcher, \& Page, 1953; Brown \& Page, 1952). Therefore, those with small foot dimensions whose feet cool quickly may be at greater risk of cool sensitisation and possibly $\mathrm{NFCl}$.

In the present study, when comparing the two visits made by females, during the inactive and active pill phases, the rate of toe skin cooling and reduction in toe skin blood flow were similar, consequently the second hypothesis is rejected. Previous research also found similar rates of cooling and change in skin blood flow between the menstrual phases, when investigating forearm and hand cooling (Charkoudian, Stephens, Pirkle, Kosiba, \& Johnson, 1999) and whole body cooling (Stephens et al., 2002). Despite the similar rate of cooling and change in 
skin blood flow in the later study, the mechanisms contributing to vasoconstriction may have been different between the phases of the menstrual cycle. The work of Stephens et al., (2002) has shown that a greater contribution from non-noradrenergic vasoconstrictor mechanisms occurs in the active pill phase than in the inactive pill phase. Therefore the present study extends the work of Charkoudian et al., (1999) and Stephens et al., (2002) to cooling of the glaborous skin of the soles of the feet, however further research establishing the mechanisms contributing to vasoconstrictor responses throughout the menstrual cycle is required.

Perceptual votes for thermal comfort and temperature sensation tracked skin temperature, with greater discomfort and reports of cooler skin sensations as skin temperature cooled. When toe skin temperature of males and females was similar, subjective votes of thermal comfort and temperature sensation were also similar. Conversely, towards the end of the cooling period, the less thermally comfortable votes reported by females compared to males were in response to the cooler foot temperatures experienced by females (Figure 3 ). This suggests that males and females have a similar perception of thermal comfort and temperature sensation; therefore the third hypothesis can be rejected. Additionally, no differences were found in perceptual votes between the females visits during the inactive and active pill phases, therefore the fourth hypothesis can be accepted. It also appears that there are some relationships between foot dimensions and subjective indicators of temperature sensation (see Table 2 and regression analysis). Consequently, as those with smaller foot dimensions may have faster rates of toe skin cooling and start to perceive foot cooling and/or thermal discomfort they should take action to prevent their feet from cooling further. Further cooling or a greater 'dose' of cold may place those with smaller foot dimensions at greater risk of cold sensitivity or a non-freezing cold injury that those with larger feet that cool more slowly may not experience.

In conclusion, the feet of females cooled at a faster rate than those of males in response to the same conductive cooling stimulus to the soles of the feet. When 
comparing males and females, similar reductions in toe skin blood flow were found for the same change in toe skin temperature, and males had larger foot dimensions than females, with the faster rate of toe skin cooling associated with smaller foot dimensions. Therefore, the effect of sex on foot cooling may be due to the differing dimensions of the feet of males and females. However, further research including males and females matched for foot dimensions should be undertaken to confirm this hypothesis. In addition, no intra-menstrual differences were found in toe skin temperature cooling profiles, in toe skin blood flow or perceptual votes between the inactive and active menstrual phases of females.

\section{References}

Bartelink, M., de Wit, A., Wollersheim, H., Theeuwes, A., \& Thien, T. (1993). Skin vascular reactivity in healthy subjects: influence of hormal status. J Appl Physiol, 74(2), 727-732.

Brown, G., Hatcher, J., \& Page, J. (1953). Temperature and blood flow in the forearm of the Eskimo. Journal of Applied Physiology, 5(8), 410-420.

Brown, G., \& Page, J. (1952). The Effect of Chronic Exposure to Cold on Temperature and Blood Flow of the Hand. Journal of Applied Physiology, 5(5), 221-227.

Canker, K., \& Finderle, Z. (2003). Gender differences in cutaenous vascular and autonomic nervous response to local cooling. Clin Auton Res, 13, 214-220.

Charkoudian, N., Stephens, D. P., Pirkle, K., Kosiba, W. A., \& Johnson, J. M. (1999). Influence of female reproductive hormones on local thermal control of skin blood flow. J Appl Physiol, 87, 1719-1723.

Colucci, W., Gimbrone, M., Jr, McLaughlin, M., Halpern, W., \& Alexander, R. (1982). Increased vascular catecholamine sensitivity and alpha-adrenergic receptor affinity in female and estrogen-treated male rats. Circulation Research, 50(6), 805-811.

Cooke, J. P., Creager, M. A., Osmundson, P. J., \& Shepherd, J. T. (1990). Sex differences in control of cutaneous blood flow. Circulation, 82(5), 16071615.

Davey, M., Eglin, C., House, J., \& Tipton, M. (2013). The contribution of blood flow to the skin temperature responses during a cold sensitivity test. Eur J Appl Physiol, 113(9), 2411-2417. doi: 10.1007/s00421-013-2678-8

Geng, Q., Holmer, I., Hartog, D. E., Havenith, G., Jay, O., Malchaire, J., . . . Rissanen, S. (2006). Temperature limit values for touching cold surfaces with the fingertip. Ann Occup Hyg, 50(8), 851-862. doi: 10.1093/annhyg/mel030 
Golja, P., Tipton, M., \& Mekjavic, I. (2003). Cutaneous thermal thresholds - the reproducibility of their measurements and the effect of gender. Journal of Thermal Biology, 28, 341-346.

Harju, E.-L. (2002). Cold and warmth perception mapped for age, gender, and body area. Somatosensory \& Motor Research, 19(1), 61-75. doi: doi:10.1080/08990220120113057

Imray, C., H, E., Grieve, A., Dhillon, S., \& The Caudwell Xtreme Everest Research Group. (2009). Cold damage to the extremities: frostbite and non-freezing cold injuries. Postgraduate Medical Journal, 85, 481-488.

Jay, O., \& Havenith, G. (2004a). Finger skin cooling on contact with cold materials: a comparison between male and female responses during short-term exposures. Eur J Appl Physiol, 91(4), 373-381. doi: 10.1007/s00421-003-0986-0

Jay, O., \& Havenith, G. (2004b). Finger skin cooling on contact with cold materials: an investigation of male and female responses during shortterm exposures with a view on hand and finger size. Eur J Appl Physiol, 93(1-2), 1-8. doi: 10.1007/s00421-004-1146-x

Jay, O., \& Havenith, G. (2004c). Skin cooling on contact with cold materials: the effect of blood flow during short-term exposures. Ann Occup Hyg, 48(2), 129-137.

Mercuro, G., Pitzalis, L., Podda, A., Zoncu, S., Pilia, I., Melis, G., \& Cherchi, A. (1999). Effects of acute administration of natural progesterone on the peripheral vascular responsiveness in healthy postmenopausal women. American Journal of Cardiology, 84, 214-218.

Nilsson, G. E., Tenland, T., \& Oberg, P. A. (1980). Evaluation of a laser Doppler flowmeter for measurement of tissue blood flow. IEEE Trans Biomed Eng, 27(10), 597-604. doi: 10.1109/TBME.1980.326582

Reading, J., Roberts, D., \& Prusaczk, W. (1997). Gender differences in finger tempeartures during cold air exposure. Naval Health Research Centre Report, 97-37.

Rissanen, S., Rintamaki, H., \& Group, C. R. (2000). Individual variation dueing slow and rapid contact cooling. Paper presented at the Internationation Congress on Environmental Ergonomics, Dortmund, Germany.

Soderberg, K., Sundstrom Poromaa, I., Nyberg, S., Backstrom, T., \& Nordh, E. (2006). Psychophysically determined thresholds for thermal perception and pain perception in healthy women across the menstrual cycle. Clin J Pain, 22(7), 610-616. doi: 10.1097/01.ajp.0000210904.75472.63

Stephens, D. P., Bennett, L. A. T., Aoki, K., Kosiba, W. A., Charkoudian, N., \& Johnson, J. M. (2002). Sympathetic nonnoradrenergic cutaneous vasoconstriction in women is associated with reproductive hormone status. American Journal of Physiology - Heart and Circulatory Physiology, 282(1), H264-H272.

Zhang, Y., \& Zhao, R. (2008). Overall thermal sensation, acceptability and comfort. Building and Environment, 43(1), 44-50. doi: DOI: 10.1016/j.buildenv.2006.11.036 


\section{Acknowledgements}

The authors would like to thank the volunteers for their forbearance and Geoff Long, Alex Ouzounologu and Danny White for their technical support and W.L. GORE \& Associates for sponsoring the research.

\section{Conflicts of interest}

The authors of the study have no conflicts of interest that could be construed as influencing the position presented in this paper.

\section{Ethical Considerations}

The study was approved by the University of Portsmouth Biosciences Research Ethics Committee and conducted under the guidelines of the Declaration of Helsinki and Council of Europe (2005) additional protocol to the convention on human rights and biomedicine concerning biomedical research. 


\section{Figures and Tables}

Table 1. Characteristics of participants expressed as means (Standard Deviation, $\mathrm{SD})$

Table 2. Correlations between foot dimensions and change in toe skin temperature, reduction in skin blood flow and temperature sensation recorded at the end of the cooling profile. * Significant correlation $(P<0.05)$

Table 3. Foot dimensions, cooling rates and change in skin blood flow of males and female volunteers with similar foot dimensions.

Figure 1. Mean (SD) change in temperature of the tip of the right great toe of males and females when the foot is in contact with a gradually cooling plate. The water outlet temperature of the water perfusing the aluminium alloy plate is plotted as a surrogate for the temperature of the plate. Males $n=12$ (Black lines), Females $n=12$ unless otherwise stated (Grey lines). * Indicates a difference between males and females $(P<0.05)$.

Figure 2. Mean (SD) normalised great toe skin blood flow against the tip of toe temperature. Males $n=12$ (Black Lines), Females $n=12$ unless otherwise stated (Grey lines). * Indicates a difference between males and females $(P<0.05)$.

Figure 3. Mean (SD) reduction in great toe skin blood flow of male and females when skin temperature was reduced by $1^{\circ} \mathrm{C}$ and $2^{\circ} \mathrm{C}$. $n=24$, filled circles males and open circles females.

Figure 4. Correlation between the total volume of the right foot and the rate of cooling of the tip of the right Great toe when the sole of the foot was in contact with a gradually cooling plate. $n=24$, filled circles males and open circles females. (Line of best fit included $r=0.728, P<0.001$ )

Figure 5. Mean (SD) foot thermal comfort values for males and females against mean tip of toe temperature. Data are plotted for votes recorded for footplate water outlet temperatures between $35^{\circ} \mathrm{C}$ to $15{ }^{\circ} \mathrm{C}$. Closed circles = males data, open circles $=$ females. $*$ Indicates a difference in thermal comfort and toe skin temperature between males and females $(P<0.05)$. 
Table 1.

\begin{tabular}{|l|c|c|c|c|c|c|c|c|c|c|}
\hline & $\mathrm{n}$ & $\begin{array}{c}\text { Age } \\
(\text { years })\end{array}$ & $\begin{array}{c}\text { Height } \\
(\mathrm{m})\end{array}$ & Mass $(\mathrm{kg})$ & $\begin{array}{c}\text { Foot } \\
\text { length } \\
(\mathrm{cm})\end{array}$ & $\begin{array}{c}\text { Great Toe } \\
\text { circumference } \\
(\mathrm{cm})\end{array}$ & $\begin{array}{c}\text { Foot Contact } \\
\text { surface area } \\
\left(\mathrm{cm}^{2}\right)\end{array}$ & $\begin{array}{c}\text { Great Toe } \\
\text { length } \\
(\mathrm{cm})\end{array}$ & $\begin{array}{c}\text { Foot } \\
\text { volume } \\
\left(\mathrm{cm}^{3}\right)\end{array}$ & $\begin{array}{c}\text { Contact } \\
\text { area:Volume } \\
\text { ratio }\end{array}$ \\
\hline Male & 12 & $29(9)$ & $1.77(0.05)$ & $76.2(10.7)$ & $27.8(0.7)$ & $8.9(0.6)$ & $76.0(12.9)$ & $7.5(0.4)$ & $805.5(65.0)$ & $0.09(0.01)$ \\
\hline Female & 12 & $28(7)$ & $1.65(0.04)$ & $66.7(11.1)$ & $24.9(1.0)$ & $7.5(0.6)$ & $67.9(11.7)$ & $6.4(0.5)$ & $621.0(63.8)$ & $0.10(0.01)$ \\
\hline & & & $P<0.001$ & $P<0.036$ & $P<0.001$ & $P<0.001$ & $P=0.059$ & $P<0.001$ & $P<0.001$ & $n .5$ \\
\hline
\end{tabular}

Table 2.

\begin{tabular}{|l|l|c|c|c|c|c|}
\hline & & Foot volume $\left(\mathrm{cm}^{3}\right)$ & Foot length $(\mathrm{cm})$ & $\begin{array}{c}\text { Foot contact area } \\
\left(\mathrm{cm}^{2}\right)\end{array}$ & $\begin{array}{c}\text { Great Toe length } \\
(\mathrm{cm})\end{array}$ & $\begin{array}{c}\text { Great Toe } \\
\text { circumference }(\mathrm{cm})\end{array}$ \\
\hline $\begin{array}{l}\text { Change in great } \\
\text { toe temperature } \\
\left({ }^{\circ} \mathrm{C} . h r^{-1}\right)\end{array}$ & All & $r=0.750(P<0.001)^{*}$ & $r=0.635(P=0.001)^{*}$ & $r=0.706(P<0.001)^{*}$ & $r=0.690(P=0.003)^{*}$ & $r=0.650(P=0.006)^{*}$ \\
\cline { 2 - 7 } & Females & $r=0.655(P=0.010)^{*}$ & $r=0.007(P=0.491)$ & $r=0.783(P=0.001)^{*}$ & $r=0.133(P=0.340)$ & $r=-0.011(P=0.487)$ \\
\hline \begin{tabular}{l} 
Reduction in $\begin{array}{l}\text { Skin blood flow } \\
(\%)\end{array}$ \\
\cline { 2 - 7 }
\end{tabular} & All & $r=0.374(P=0.115)$ & $r=0.312(P=0.162)$ & $r=0.304(P=0.168)$ & $r=0.049(P=0.440)$ & $r=-0.081(P=0.402)$ \\
\cline { 2 - 8 } & Memales & $r=0.603(P=0.018)^{*}$ & $r=0.566(P=0.002)^{*}$ & $r=0.337(P=0.054)$ & $r=0.512(P=0.005)^{*}$ & $r=0.578(P=0.002)^{*}$ \\
\hline \multirow{2}{*}{$\begin{array}{l}\text { Temperature } \\
\text { sensation }\end{array}$} & All & $r=0.109(P=0.368)$ & $r=0.271(P=0.197)$ & $r=0.056(P=0.431)$ & $r=0.245(P=0.222)$ & $r=0.102(P=0.376)$ \\
\cline { 2 - 8 } & Females & $r=0.429(P=0.018)^{*}$ & $r=0.288(P=0.086)$ & $r=0.150(P=0.243)$ & $r=0.288(P=0.086)$ & $r=0.586(P=0.001)^{*}$ \\
\cline { 2 - 8 } & Males & $r=0.002(P=0.498)$ & $r=-0.095(P=0.389)$ & $r=0.221(P=0.245)$ & $r=0.207(P=0.260)$ & $r=0.426(P=0.084)$ \\
\hline
\end{tabular}


Table 3.

\begin{tabular}{|l|c|c|c|c|c|c|}
\hline & $\begin{array}{c}\text { Foot volume } \\
\left(\mathrm{cm}^{3}\right)\end{array}$ & Toe length $(\mathrm{cm})$ & $\begin{array}{c}\text { Great Toe } \\
\text { circumference } \\
(\mathrm{cm})\end{array}$ & $\begin{array}{c}\text { Foot contact } \\
\text { area }\left(\mathrm{cm}^{2}\right)\end{array}$ & $\begin{array}{c}\text { Change in great } \\
\text { toe } \\
\text { temperature } \\
\left({ }^{\circ} \mathrm{C} . \mathrm{hr}^{-1}\right)\end{array}$ & $\begin{array}{c}\text { Change in skin blood } \\
\text { flow with a }{ }^{\circ} \mathrm{C} \\
\text { reduction in skin } \\
\text { temperature }(\%)\end{array}$ \\
\hline Female 1 & 665 & 6.8 & 7.2 & 70.2 & -16.0 & -36.9 \\
\hline Female 2 & 679 & 6.2 & 6.8 & 76.7 & -17.1 & -40.7 \\
\hline Female 3 & 687 & 6.7 & 7.3 & 68.0 & -14.8 & -27.3 \\
\hline Mean & 677 & 6.6 & 7.1 & 71.6 & -16.0 & -35.0 \\
\hline & & & & & & \\
\hline Male 1 & 720 & 7.5 & 8.5 & 77.5 & -17.4 & \\
\hline Male 2 & 734 & 7.9 & 8.8 & 73.5 & -15.8 & -46.6 \\
\hline Male 3 & 761 & 8.0 & 8.8 & 74.0 & -17.1 & -25.6 \\
\hline Mean & 738 & 7.8 & 8.7 & 75.0 & -16.8 & -15.8 \\
\hline
\end{tabular}




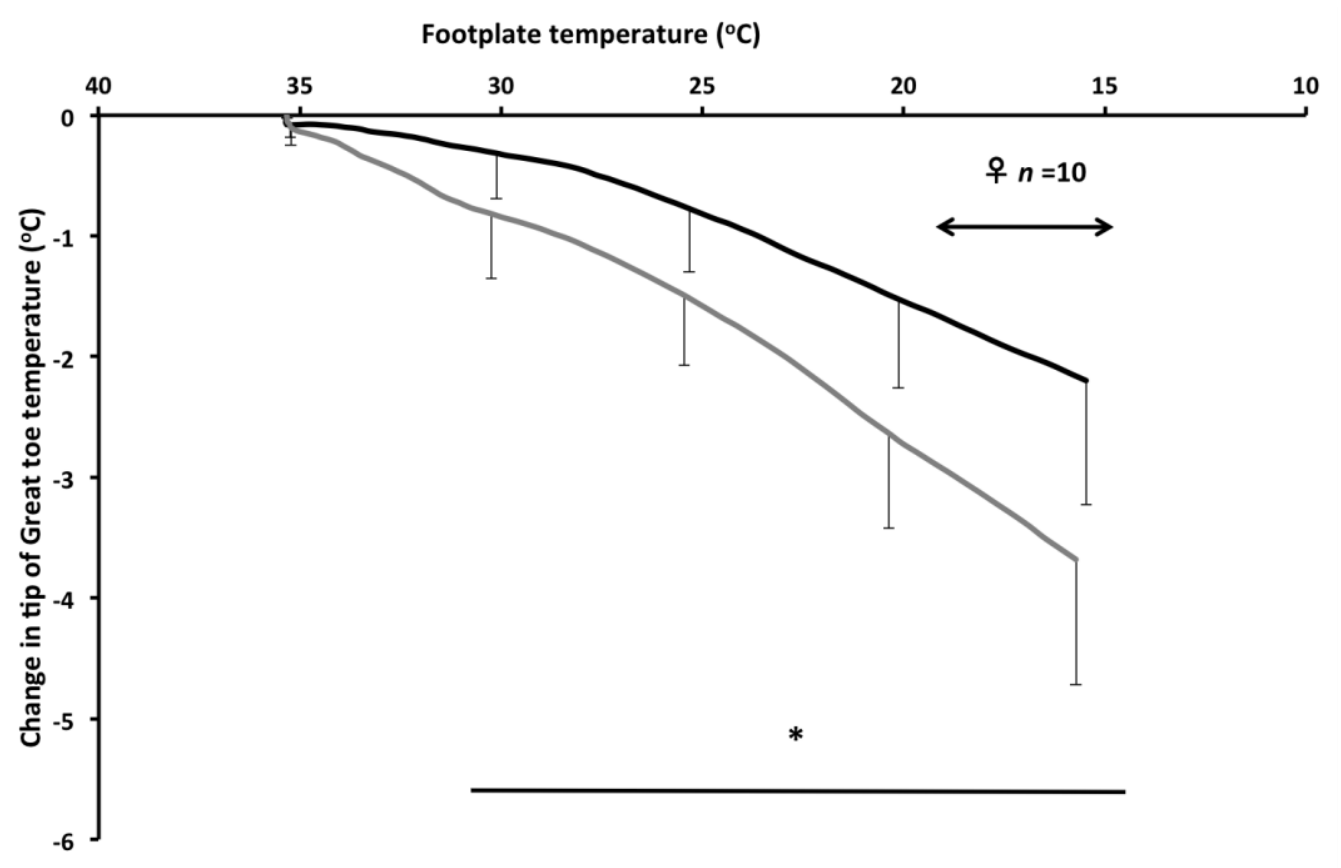

Figure 1 


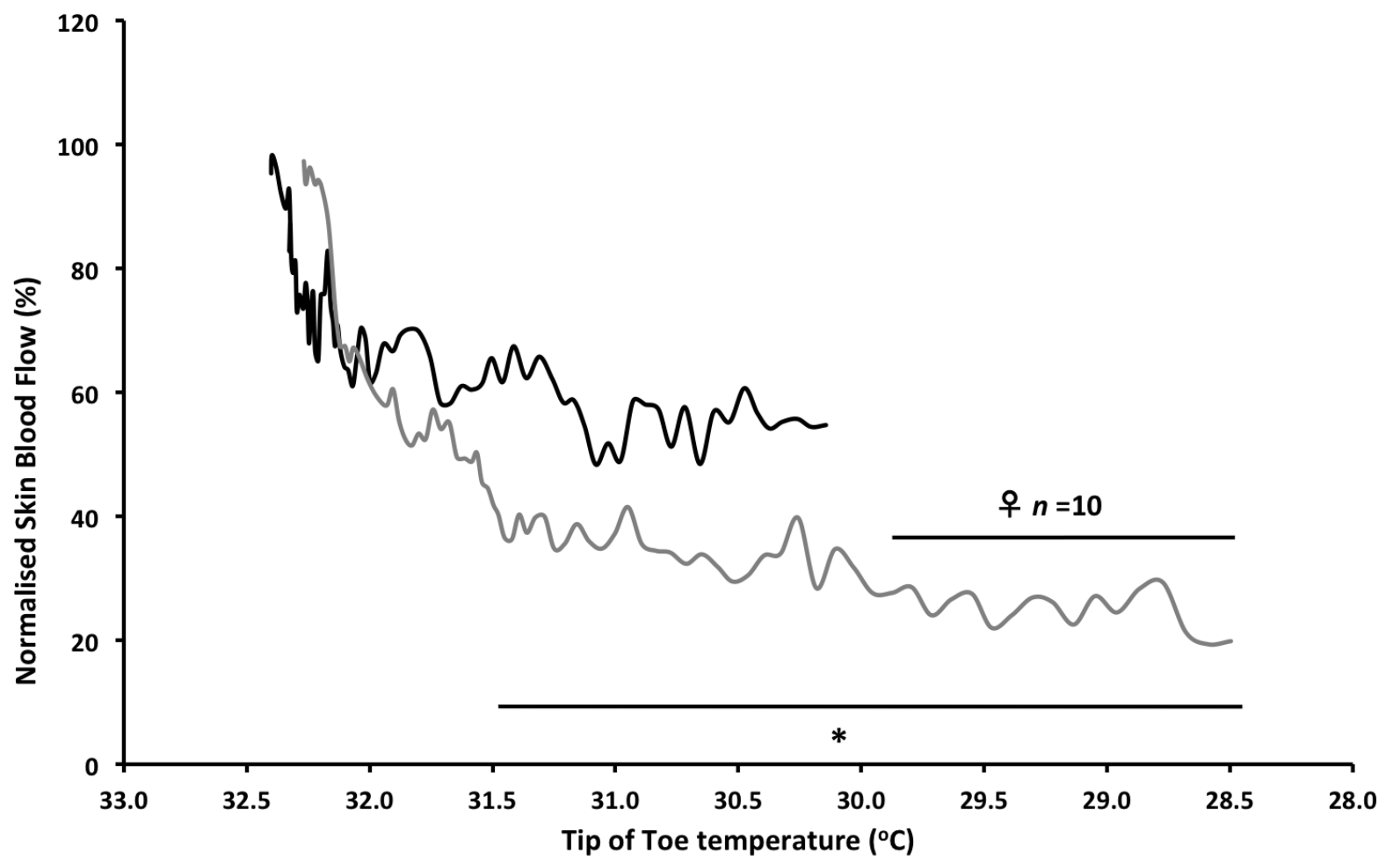

Figure 2. 


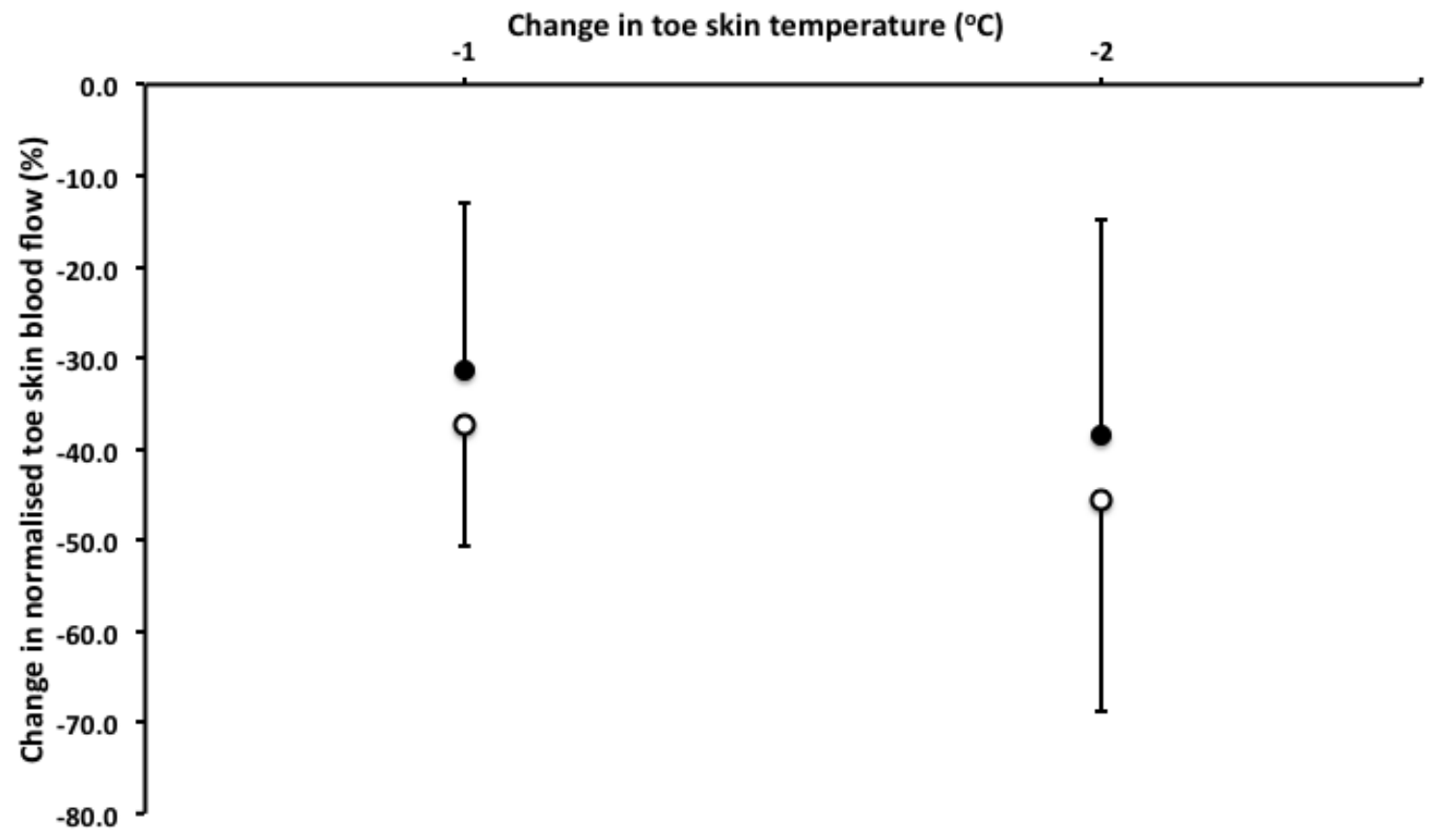

Figure 3. 


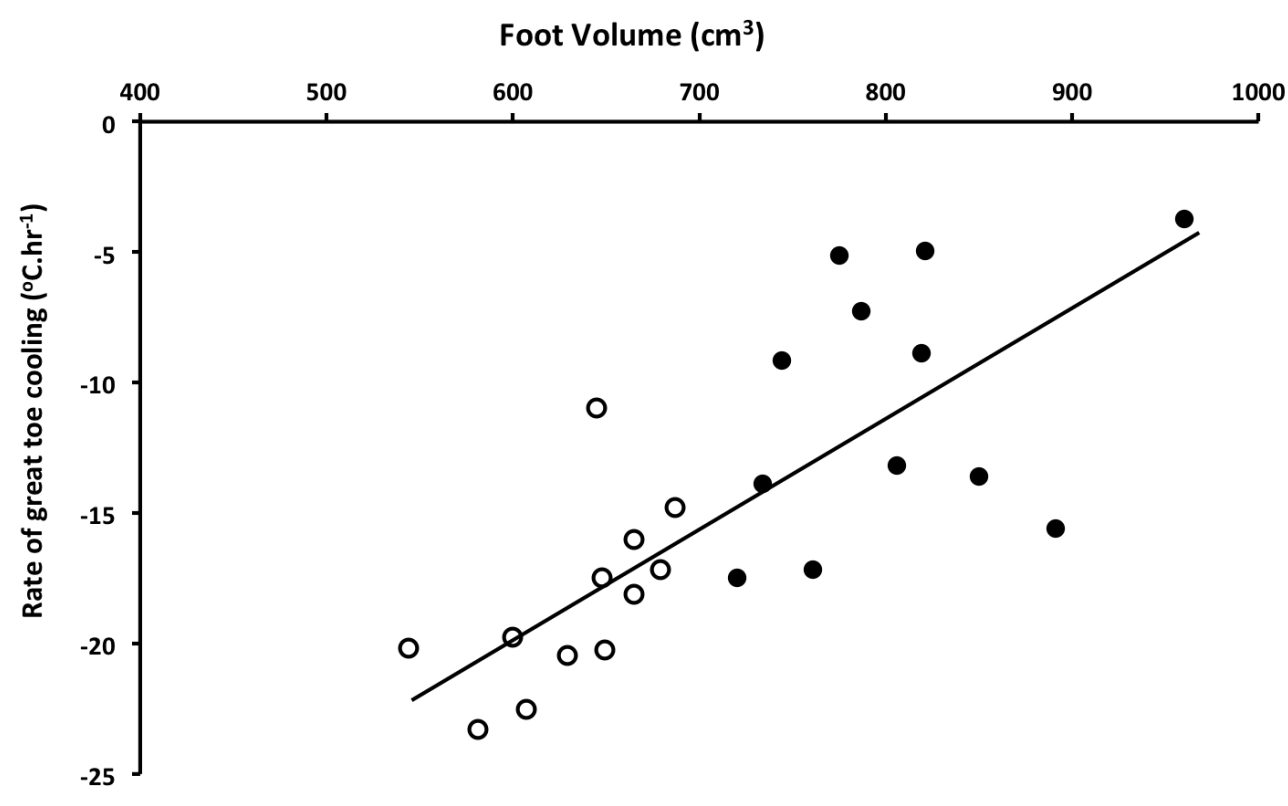

Figure 4. 


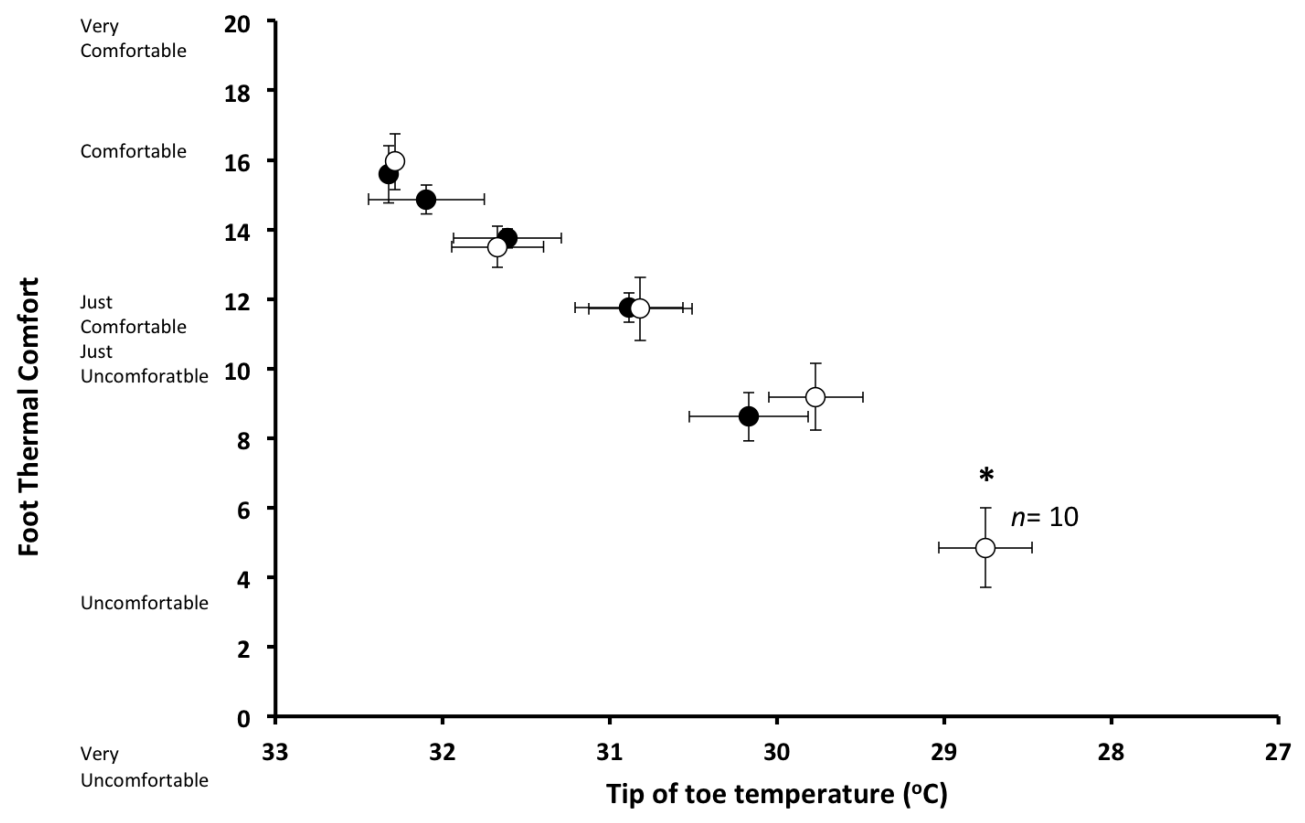

Figure 5. 